\title{
INVENTÁRIO E ANÁLISE DA ARBORIZAÇÃO DE VIAS PÚBLICAS DE MARINGÁ-PR
}

\author{
André Cesar Furlaneto Sampaio ${ }^{1}$, Bruno Luiz Domingos De Angelis ${ }^{2}$
}

(recebido em 01.04.2008 e aceito para publicação em 07.06.2008)

\section{RESUMO}

A cidade de Maringá tem na sua arborização de vias públicas um bem muito valioso, que contribui significativamente para boa qualidade de vida da cidade e outros fatores, porém a qualidade desta arborização vem decrescendo a cada ano. Atualmente o gerenciamento destas árvores apresenta vários problemas e dentre os principais podemos contar a infraestrutura pequena e insuficiente, e dados para um manejo e planejamento desatualizados. Esta pesquisa pretende colaborar com a melhora do planejamento da arborização de vias públicas com uma análise geral da arborização urbana de Maringá. Dessa forma elaborouse um levantamento censitário em $72,55 \%$ da área da malha urbana do município. A análise dos dados identificaram 113 espécies de porte arbóreo, em 93.261 árvores cadastradas, sendo que, $35,52 \%$ foram cadastradas como em condições gerais ruins (danos físicos, doenças e pragas). Uma freqüência alta de ocorrência, na ordem de $39,21 \%$ da espécie Caesalpinea peltophoroides Benth. (Sibipiruna) foi observado, o que é considerado grave, sobretudo por facilitar disseminação de doenças e pragas. A área verde das árvores de vias públicas correspondeu a $25,24 / \mathrm{m}^{2} / \mathrm{hab}$. Os dados demonstram que novas diretrizes e um novo planejamento devem ser pensados com urgência para que essa exuberante arborização não continue seu declínio.

Palavras-chave: arborização urbana, censo, manejo.

\footnotetext{
1 Graduação em Eng. Florestal - Universidade Federal do Paraná (UFPR)/ Curso de pós-graduação em Gestão e Engenharia Ambiental - Instituto de Engenharia do Paraná (IEP) / Mestrando em Geografia - Universidade Estadual de Maringá-PR / Professor da pós-graduação em Planejamento Ambiental - Centro Universitário de Maringá - CESUMAR - sampaio.andre@gmail.com

2 Professor do Departamento de Agronomia, Universidade Estadual de Maringá (UEM), Maringá, PR brucagen@uol.com.br
} 


\title{
ANALYSIS OF URBAN TREES OF MARINGÁ, PARANÁ
}

\begin{abstract}
Maringá has streets very well tree-lined, a valuable characteristic of this city, which contributes significantly to the quality of life of its population. However, the quality of the urban trees has been decreasing each year; nowadays the manage of this trees shows lots of problems, from among we can say insufficient infrastructure, and out-of-date data for an effective planning and manage. This research intends to collaborate through the analysis of this tree-lined streets of the city, where a census was done and data were analysed identifying 113 species, among 93.261 catalogued trees, in which $35,52 \%$ are in passable general conditions (physical damage, diseases and plagues), a high frequence of $39,21 \%$ of the species Caesalpinea peltophoroides Benth (Sibipiruna) was observed and it is considered serious for making easyer the dissemination of diseases and plagues. A rate of $25,24 / \mathrm{m}^{2} /$ cit of green área was found at this study. Data show a good quality of this "urban environment" due of the trees, but its evident that new directions and new planning should be thought urgently in order to stop the decrease of this great valuable green city.
\end{abstract}

Key - word : Urban trees, census, manage 


\section{INTRODUÇÃO}

Maringá, fundada a 10 de maio de 1947, teve seus pioneiros, em sua maioria, vindos do Nordeste, São Paulo e Minas Gerais. Passou de distrito de Mandaguari (1947), para Vila em 1948 e em 1951 conquistou o status de Município. O traçado foi projetado pelo urbanista Jorge de Macedo Vieira e a arborização de Maringá ficou sob a responsabilidade do paisagista Dr. Luiz Teixeira Mendes, ambos contratados pela empresa colonizadora Companhia Melhoramentos do Norte do Paraná (CMNP) (TAKAHASHI, 1997).

Maringá usa até hoje como propaganda o fato de ser muito arborizada e possuir belos parques. Atrai muitos turistas e habitantes pela boa qualidade de vida e, até hoje, colhe frutos por ter tido uma iniciativa ambientalmente melhor que muitas cidades brasileiras (SAMPAIO, 2006).

Durante muitos anos a CMNP assumiu a responsabilidade de administrar a arborização da cidade, sem ônus para a administração pública. A CMNP se encarregava da compra das mudas, adquiridas na Secretaria de Agricultura de São Paulo, na Escola Superior de Agricultura "Luiz de Queiroz" de Piracicaba e no Instituto Agronômico de Campinas, sendo cuidadosamente examinadas por dois técnicos, primando sempre pela boa qualidade do seu plantio, da manutenção e da rega, feita por um caminhão tanque e, até das grades para proteção das mudas, que eram feitas na serraria da própria CMNP (TAKAHASHI, 1997).

À medida que a prefeitura foi se estruturando, assumiu essa responsabilidade, criando um Departamento denominado de Parques e Jardins, sob a orientação técnica da CMNP, que orientou a prefeitura até 1982 (TAKAHASHI, 1997).

O crescimento da cidade foi tornando o viveiro, destinado à produção das mudas para a arborização, insuficiente para atender a demanda e, a prefeitura, então, passou a comprar mudas de outros locais para a formação e manutenção de seu próprio viveiro. A infra-estrutura da prefeitura destinada aos cuidados e planejamentos da arborização não conseguiu acompanhar as necessidades para se manter a boa qualidade do "verde" maringaense.

Milano (1988), em sua a tese de doutorado, indicava que um manejo mais adequado seria vital para a manutenção da qualidade da arborização urbana.

Os anos passaram e objetivando atualizar os dados sobre a arborização de vias públicas de Maringá, este trabalho, denominado "Censo Verde" (Projeto Árvore), foi elaborado.

O trabalho em questão teve sua execução feita através do Centro Universitário de Maringá (CESUMAR), com apoio da Companhia de Energia Elétrica do Paraná (COPEL), 
da empresa fabricante de gelatinas GELITA DO BRASIL, e da empresa de Transporte Coletivo Cidade Canção (TCCC).

\section{OBJETIVO}

Realizar um inventário quali-quantitativo da arborização de vias públicas da cidade de Maringá-PR (censo de todas as árvores de vias públicas), para o estabelecimento de um banco de dados que colabore para manutenção, planejamento e manejo da arborização.

\section{MATERIAIS E MÉTODOS}

Buscando-se uma compreensão mais detalhada sobre a arborização de vias públicas de Maringá, desenvolveu-se a presente metodologia objetivando cadastrar todas as árvores de acompanhamento viário da cidade de Maringá.

\section{Formação e capacitação das equipes de campos}

Foram capacitados 40 alunos do Curso de Ciências Biológicas do Centro Universitário de Maringá (CESUMAR), por meio de treinamento teórico e prático, ministrado pelo autor deste artigo, para executar a coleta de dados do inventário. Formaram-se 10 equipes (duplas de alunos) com os alunos capacitados e selecionados, cada equipe foi identificada por uma letra do alfabeto, de $\mathrm{A}$ a J.

O conteúdo da capacitação foi dividido nas seguintes aulas (cada aula com 5 horas de duração):

- Arborização Urbana - Conceituação, importância, legislação (teórica);

- fundamentos básicos da dendrologia - definição, histórico, importância, sistemas de classificação e nomenclatura (teórica);

- terminologia Dendrológica - referente; árvore, casca, folha, flores e frutos (teórica);

- metodologia Dendrológica - coleta de material botânico, herbário florestal, metodologia de trabalho em herbário, tipos de coleção, arboretos e parques fenológicos e levantamentos dendrológicos (teórica);

- espécies da arborização urbana de Maringá - Características; porte, sistema radicular, copa, flores e frutos (teórica);

- visita as ruas de Maringá para treino de identificação de espécies arbóreas. (Prática); 
- informações urbanas - Estrutura urbana de Maringá e seu convívio com as espécies vegetais (teórica);

- implantação e manejo da arborização urbana - planejamento, plantio e condução da arborização, podas, transplantes, dendrocirurgias e remoções. *Técnicas e cuidados a serem observados no trato da arborização urbana (teórica);

- redes de Energia Elétrica - estrutura, composição, funcionamento, manutenção, conseqüências de conflitos, riscos de aproximação nas atividades de conservação da arborização (teórica);

- redes de águas - estrutura, composição, funcionamento, manutenção, problemas causados pela arborização (teórica);

- explicação de manuseio dos equipamentos de campo: palm-top, máquinas fotográficas (teórica);

- explicação do manual de preenchimento do formulário digital de campo do levantamento quali-quantitativo total de Maringá (teórica);

- visita as ruas de Maringá para treino de medições dendrométricas, principalmente medições de altura, onde os treinos foram feitos com hipsômetros (prática);

- metodologia para identificação das condições gerais das árvores;

- revisão geral dos assuntos abordados.(teórica);

- especificações finais referentes ao projeto (teórica);

- simulação de trabalho de campo (prática) - uma semana de simulação;

Dos 40 alunos capacitados foram selecionados 20 para participarem do trabalho de campo. A seleção final foi feita através de provas de acurácia nas estimativas de altura, medições dendrométricas, identificação das espécies e classificação das condições gerais das árvores. Todos os alunos selecionados receberam bolsas para exercerem a coleta de dados, sendo que 5 horas por dia (dias úteis) era o tempo destinado a essa coleta.

\section{Coleta de dados}

A partir de uma base cartográfica digitalizada do Município de Maringá, datada de 1995, formato DWX e DXF e arquivo DATUM - SAD 69, com as árvores plotadas a partir de análise de foto aérea e sistema de coordenadas UTM, obteve-se acesso a 550 pranchas (mapas que foram adquiridos através da colaboração da COPEL) em escala 1:1000. Cada prancha utilizada continha uma parte da cidade com as árvores já plotadas em sua provável 
posição e um número identificador denominado feature number, esse mesmo número foi usado para se identificar o registro que teve seus dados cadastrados in loco. As equipes foram distribuídas isoladamente em pranchas diferentes, e a cada prancha finalizada se começava uma nova. Todos os features numbers das pranchas tiveram de ter seus dados coletados.

A coleta de campo teve início em março de 2004 e foi finalizada no final de agosto de 2005.

As informações referentes a cada feature number foram cadastradas, em aparelhos palm top de marca Tungsten e modelo Tungsten - E. Foi elaborado um programa de cadastramento específico para este aparelho (seguindo as diretrizes dos dados a serem coletados) por uma equipe de informática do CESUMAR. As informações foram descarregadas, validadas e analisadas para compor um relatório final.

Cada equipe de campo ficou responsável pelo registro das seguintes informações:

a) Quanto à identificação e localização do registro:

Feature Number (FN) - Número identificador do registro que consta nas pranchas da cidade de Maringá-PR. Número da Prancha (PRC) - Número da prancha (mapa fornecido pela Companhia de Energia Elétrica do Paraná). Logradouro (Via) - Nome da rua, avenida, praça, etc. Número do Imóvel (NI) - Número do imóvel em frente ao feature number (registro) que está sendo cadastrado. Número do Quarteirão (NQ) - As equipes de campo numeram todos os quarteirões das pranchas em que trabalharam com a letra que foi designada para cada equipe e número em seqüência - Exemplo - Quarteirão A1, Quarteirão A2. Zona (Z) - Número da zona verificada. Lado da Rua (LR) - Para saber se o registro cadastrado está no lado par, no lado impar ou no canteiro central das vias públicas de Maringá-PR. Status (S) - Para identificar o tipo de registro, o qual foi separado nas seguintes categorias: regular - árvore viva com mais de 3 metros de altura; jovem - árvore viva com até 3 metros de altura; morta - árvore morta ou que, devido a danos de doenças, pragas e outros aparenta estar morta; cortada - toco de uma árvore que existia no local, ou vestígios evidentes da existência anterior no local dessa árvore; ausente - registro (feature number) que consta no mapa, mas não consta in loco ou, área livre vazia de vestígios da existência de árvore que poderia ter existido no local. Direção de Cadastro - Esse campo foi designado principalmente para se saber o caminhamento da equipes de campo, nele foi colocado o próximo feature number a ser cadastrado.

b) Quanto a identificação da espécie:

Espécie (SP) - Nome popular e científico da espécie a ser registrada.

c) Quanto ao porte:

Altura Total $(\mathrm{H})$ - Altura estimada em metros de toda parte superficial da árvore. Altura da Primeira Bifurcação $(\mathbf{H b})$ - Altura medida com trena do solo até a primeira bifurcação ou 
galho. Circunferência a Altura do Peito (Cap) - Circunferência do tronco medida a 1,30 metros do solo, em metros. Diâmetro de Copa longitudinal (Long) - Medição do diâmetro de copa longitudinalmente ao meio fio, em metros. Raio de Copa lado da Rua (Rr) Medida do raio de copa sentido tronco - rua, em metros. Raio de Copa lado Lotes (Construções) (Rc) - Medida do raio de copa sentido tronco-construções, em metros.

d) Quanto a posição de plantio:

Distância da Árvore até o meio Fio (Mf) - Medida do centro do tronco até o meio fio, em metros. Distância da Árvore até as construções (Ct) - Medida do centro do tronco da árvore até a construção, em metros. Espaçamento (E) - Medida do feature number (registro) que se está cadastrando até o próximo a ser cadastrado (direção de cadastro).

\section{e) Quanto a Rede Elétrica:}

Tipo de Rede Elétrica (Re) - Os tipos de rede elétrica identificados foram: Rede Elétrica Compacta $(A)$ - Rede em que a área de poda é reduzida e os cabos ficam mais próximos um do outro e tem uma capa protetora que não isola totalmente, mas protege de forma satisfatória; rede elétrica simples (B) - Rede sem capa de proteção nos fios, tem distância maior entre eles e a área de poda é maior; sem rede elétrica $(C)$ - Quando o local não apresenta rede elétrica; apenas Baixa tensão (D) - Quando a fiação elétrica só contém os fios de baixa tensão.

\section{f) Quanto aos aspectos Fenológicos:}

Folhas (Fo) - Conforme o Plano Diretor de Arborização de Vias Públicas de Porto Alegre (2000) se cadastrou a quantidade de folhas da seguinte maneira: sem folhas - quando a árvore não apresentava nenhuma folha aparente em seus galhos; com poucas folhas quando a árvore apresentava vários galhos sem folhas ou um raleamento bastante evidente de folhas (aproximadamente $50 \%$ da copa desfolhada); com muitas folhas - Quando a árvore apresentava uma distribuição onde todos os galhos apresentavam folhas. Flores (Flo) -. Conforme o Plano Diretor de Arborização de Vias Públicas de Porto Alegre (2000) se cadastrou a quantidade de flores da seguinte maneira: sem flores (A) - quando a árvore não apresentava nenhuma flor aparente em seus galhos; com poucas flores (B) - Quando a árvore apresentava até $50 \%$ de sua floração, levando em consideração a espécie; com muitas flores (C) - quando se apresentava com toda sua capacidade de floração, levandose em consideração a espécie. Frutos (Fr) - Conforme o Plano Diretor de Arborização de Vias Públicas de Porto Alegre (2000) se cadastrou a quantidade de frutos da seguinte maneira: sem frutos $(A)$ - quando a árvore não apresentava nenhum fruto aparente em seus galhos; com poucos frutos $(B)$ - quando a árvore apresentava até $50 \%$ de sua frutificação evidente, levando-se em consideração a espécie, com muitos frutos (C) quando a árvore apresentava toda sua capacidade de frutificação evidente, levando-se em consideração a espécie. 
Os dados em relação á fenologia (folhas, frutos e folhas) foram analisados separadamente com o intuito de colaborar em pesquisas sobre o comportamento fenológico das várias espécies encontradas, porém, essa análise fenológica faz parte de outras pesquisas que ficaram vinculadas a este projeto.

\section{g) Quanto a Necessidade de Manejo:}

Poda Recomendada (PR) - O treino de capacitação visou capacitar as equipes de campo para recomendar duas das podas mais importantes na arborização urbana e essa necessidade foi cadastrada com os seguintes tópicos: poda não necessária $(A)$ - Quando dentre as podas indicadas neste campo não houver necessidade de nenhuma; poda de limpeza (B) - quando existiam galhos grandes secos e doentes, ou vários galhos pequenos também secos ou doentes, principalmente quando o risco de queda do galho era evidente; poda de rede elétrica $(C)$ - Quando eram presentes um ou mais galhos encostando na rede elétrica de formar a futuramente causar problemas, ou até já estar causando problemas. Copa (Co) - Dado coletado quando o status do feature number (registro) era designado como regular ou jovem. Este dado foi cadastrado com os seguintes itens: sem interferência (A) - Quando a copa não se mostrava interferindo o trânsito de pedestres ou veículos; interferindo o trânsito de veículos (B) - Quando a copa se mostrava interferindo o trânsito de veículos; interferindo o trânsito de pedestres $(C)$ - Quando a copa interferia o trânsito de pedestres.

h) Quanto à qualidade:

Área Livre (Al) - Medida da área livre de pavimentação, onde cresce a árvore, em metros quadrados.

Condição do Sistema Radicular (SisRad) - Seguindo o Plano Diretor de Arborização de Vias Públicas de Porto Alegre (2000) foram feitas as seguintes denominações para classificar o sistema radicular: sem afloramento (A) - Não se tem visualização da raiz, pois esta se encontra totalmente de forma subterrânea; com afloramento dentro da área Livre (B) - Raiz visível dentro da área livre de pavimentação; afetando calçada (C) - Raiz de forma superficial, ultrapassando a área de crescimento e provocando rachaduras nas calçadas; afetando construção (D) - Raiz de forma superficial formando rachaduras nas construções próximas; afetando rede subterrânea de forma evidente $(E)$ - Raiz que evidentemente causou danos a rede subterrânea de água e esgoto.

Infestação de Cupim (Icupim) - Verificação da presença de cupins ou vestígios da passagem destes pela árvore em questão. Esse dado foi verificado apenas na parte visível da árvore, não foi verificada a presença de cupins subterrâneos. Focou-se a verificação na observação de ninhos arborícolas nos galhos, caminhos de cupins nos troncos e galerias de cupins formadas em troncos e galhos. 
Fungos (F) - Foi indicada a presença de fungo quando era verificada a presença de corpo de frutificação aparente na base, no tronco ou em galhos.

Epífitas (Ep) - Verificação da presença de epífitas nas árvores e quais epífitas são estas. Considerou-se as seguintes epífitas: musgos, liquens, samambaias, figueiras, cactáceas e trepadeiras.

Podas Anteriores (PodaA) - Verificação da presença de poda executada na árvore. A verificação foi dividida em três itens: com poda anterior $(A)$ - Quando foi visível que existiu retirada de galhos da árvore, mas nenhum desses galhos apresentava rebrotas; poda com brotos (B) - Quando foi visível a retirada de galhos e esses possuíam rebrotas; $\underline{\text { sem poda }}$ anterior (C) - Quando não ficou evidente que ocorreram retiradas de galhos; com poda drástica (D) - Quando a poda executada se mostrou desequilibrando a árvore, ou quando visivelmente galhos em excesso foram retirados (quando observada foi considerada como injúria mecânica grave).

Condição Geral (C) - Seguindo a indicação de Milano (1988) se considerou três classes de qualidade, divididas da seguinte forma: Condição Geral Boa (1) - Árvore aparentemente boa, vigorosa, que apresenta poucos ou nenhum sinal de pragas, doenças ou injúrias mecânicas, que apresenta a forma característica da espécie e não requer trabalhos de correção de grande amplitude; Condição Geral Satisfatória (2) - Árvore com condição e vigor médios para o local, pode apresentar problemas de pragas, doenças ou injúrias mecânicas, poda de limpeza, reparos de danos físicos ou controle de pragas e doenças; Condição Geral Ruim (3) - Árvore que apresenta estado geral indicando declínio e pode apresentar severos danos de pragas, doenças ou danos físicos sérios ou em estágio avançado, embora muitas vezes não aparente morte eminente, pode requerer muito trabalho de recuperação.

Este dado foi colocado como sendo o último a ser preenchido pelas equipes de campo, pois durante o preenchimento de todos os outros dados era possível visualizar vários aspectos importantes para determinação deste. O treinamento das equipes de campo focou essa análise nos aspectos que foram considerados mais comuns e de maior facilidade visual de identificação nas árvores urbanas. Os bolsistas tiveram intenso treinamento em campo, para evitar subjetividades, porém, com certeza essas existiram, pois á análise visual de aspectos nas árvores muitas vezes formam linhas tênues na divisa do que é uma má condição e uma condição média de uma árvore. Os vários aspectos observados foram classificados como graves, médios e pequenos:

* Presença de cupins - Classificado como grave, pois indicam cavidades e madeira em decomposição.

* Presença de fungos - Classificado como médio, pois são sinais evidentes de deterioração da madeira, porém, foi considerado como em menor escala que cupins. 
* Necessidade de poda de limpeza - Quando era observada a necessidade de pode de limpeza, essa condição era tida como de importância média para a classificação da condição da árvore, pois tendo a necessidade desta poda isso implicava na existência de vários galhos mortos e secos.

* Erva-de-passarinho - Classificado como grave quando tomava mais de $50 \%$ da copa. Quando era existente, porém em porcentagem menor que $50 \%$ foi classificado como médio. A erva de passarinho é vista como um sintoma claro de árvores estressadas.

*Cancro - O cancro foi definido como um sintoma associado a presença de fungos (Sphaeropsis sapinea, Phytophthora spp. , Cryphonectria cubensis , Valsa ceratosperma, Botryospheria e outros). Para sua identificação nas árvores era observada a presença de lesões margeadas de calos, com a morte do câmbio e de parte da circunferência do tronco. Foi classificado como grave quando as lesões observadas eram maiores que um palmo e rodeavam toda a circunferência do tronco, ou quando existiam lesões maiores que dois palmos. Quando verificada a presença dos cancros fora desse padrão á classificação da importância foi de valor médio.

* Cavidades - Cavidades na base das árvores foram consideradas graves, pois mesmo se pequenas em extensão, pela demora em cuidados na área urbana, se tornam um grande atrativo para pragas. Cavidades grandes englobando mais de $40 \%$ do tronco fora da base da árvore também foram tidas como graves. Cavidades menores no tronco ou em galhos foram classificadas como médios.

* Injúrias mecânicas - Certas injúrias provocadas por vandalismos nas árvores podem provocar danos á saúde destas. Foram classificadas como de pequena importância desenhos, escritos, pregos e pequenos objetos no tronco. Foram classificadas como graves vestígios de fogo em cerca de $30 \%$ do tronco, anelamentos e podas unilaterais e drásticas.

* Inclinação e tortuosidade do tronco - Foram consideradas inclinadas árvores que visualmente se identificava ângulos entre a calçada e o tronco menores que $60^{\circ}$ - Classificado como grave.

* Sistema radicular - Classificado como médio quando espécies de raiz subterrâneas apresentavam raízes aflorando na área livre ou afetando o calçamento, pois nesses casos é nítida a compactação do solo, que é importante, pois influencia em muito no crescimento e extensão da raiz.

* Área livre - Quando eram observadas áreas livres menores que $1 \mathrm{~m}^{2}$ isso definia um aspecto médio na avaliação da condição da árvore, pois essa área influencia na ciclagem de nutrientes e na infiltração de água para as raízes. As áreas livres 
maiores ou iguais a $1 \mathrm{~m}^{2}$ não são tidas como adequadas para as árvores urbanas, porém, são muito comuns em praticamente todas as cidades brasileiras, desta forma quando eram observadas foram classificadas como de pequena importância para a análise da condição geral da árvore.

* Folhas amareladas - Folhas amareladas ou secas em mais de $50 \%$ da copa foi classificado como um aspecto grave, com menos de $50 \%$ foi tido como médio. Folhas amareladas foram tidas com sinais de intoxicação, déficit hídrico e nutricional das árvores.

Quando observado qualquer aspecto definido como grave a árvore foi classificada como em condição geral ruim. Quando observado somente aspectos tidos como de pequena importância á árvore foi classificada como em condição geral boa. Quando observados até dois aspectos tidos como médios a árvore foi classificada como em condição satisfatória. Quando observado mais de dois aspectos médios a decisão, em geral, ficava a cargo da análise da equipe de campo que optava por condição geral satisfatória ou ruim, a opção partia da observação da existência de outros aspectos classificados como de pequena importância.

Esta pesquisa analisou de forma visual e genérica as condições das árvores, colocando em evidência dentre os vários fatores e aspectos graves observados apenas a incidência de cupins, podas drásticas, fungos, tamanho das áreas livres e condições do sistema radicular, pois o número de dados a serem coletados era muito grande e o tempo para coletar os dados em cada árvore não era suficiente para a inserção de todos os dados. Desta forma, vários aspectos observados ficaram como sendo fatores internos na classificação final da condição geral da árvore (cancros, cavidades, folhas amareladas, inclinação do tronco e outros).

As árvores cadastradas como em condições ruins não foram consideradas como destinadas para remoção, pois legislativamente em Maringá a condenação de uma árvore só pode ser feita por profissional habilitado da Prefeitura municipal, além desse fato, a avaliação executada pelas equipes de campo não foi completa o suficiente para poder condenar essas árvores (remoção), mas com certeza a classificação feita indica eficazmente as árvores a terem prioridade nas vistorias para remoção, pois estas apresentaram bons indicadores de uma condição inadequada para sobrevivência no já tão agressivo "ambiente urbano".

\section{Processamento e análises dos dados}

Depois de constituído um banco de dados com as informações cadastradas em campo, utilizou-se dois softwares (Microsoft Exccell e Acess) para processar os dados de forma a cruzar informações e calcular índices. O processamento dos dados foi feito em 
conjunto com uma equipe de analistas de sistemas do Centro Universitário de Maringá. Os dados foram trabalhados em um computador Pentium 2.4Ghz, com 64MB de memória RAM, $100 \mathrm{MB}$ de espaço livre no $\mathrm{Hd}$, monitor com resolução 1024 x 768, mouse padrão e teclado padrão ABNT2.

\section{Cálculo da área verde das árvores de vias públicas (Área ocupada pela copa)}

O cálculo da área verde total, média e per capita disponível, feito para toda área amostrada, foi realizado com base nas áreas verdes individuais produzidas pelas espécies de árvores cadastradas na região de estudo. A área verde individual foi calculada a partir do raio médio ( $r$ ) de cada unidade de observação (árvore). O cálculo do raio médio foi realizado com uso da seguinte equação (1):

$$
r=1 / 4(\text { Long }+R r+R c)
$$

onde:

Long $\Rightarrow$ diâmetro longitudinal - paralelo à calçada;

$\mathrm{Rr} \Rightarrow$ raio em direção a rua - transversal à calçada;

$\mathrm{Rc} \Rightarrow$ raio em direção ao muro ou construção - transversal à calçada.

A área verde (AV) para cada unidade de observação foi calculada pela seguinte equação (2):

$$
\mathrm{AV}=\Pi \cdot \mathrm{r}^{2}
$$

Para se obter a área verde total foi feita uma somatória da área estimada de cada copa de cada árvore cadastrada.

\section{RESULTADOS E DISCUSSÃO}

O Projeto Árvore finalizou oficialmente a coleta de dados no dia 30 de agosto de 2005, não conseguindo atingir o objetivo de cadastrar todas as árvores de vias públicas de Maringá, pois existiram problemas orçamentários devido ao tempo estendido de trabalho de campo. Os dados que foram coletados referem-se a $72,55 \%$ da área urbana efetiva do município, porém, através do uso de imagens de satélite, fornecidas pela prefeitura municipal, foi possível estimar um cadastro de $90 \%$ da arborização de vias públicas (Figura 01).

A estimativa foi feita contabilizando os logradouros arborizados que foram cadastrados pelo inventário e descartando os que não foram. Através das imagens de satélite foi possível contabilizar, pela visualização das copas, a quantidade de árvores que não foi cadastrada. Obteve-se o número aproximado de 10.362 árvores não inventariadas $(10 \%)$, porém, essa estimativa não pode ter seu erro calculado, pois existe uma 
desatualização das imagens de 4 anos e ficaram de fora da contabilidade mudas de árvores, que não ficaram visíveis nas imagens.

Milano (1988), considerando uma precisão de amostragem de $95 \%$ de probabilidade e com limite de erro de 10\%, efetuou amostragem aleatória com 15 unidades amostrais de 200 x 500 metros, distribuídas por toda zona urbana de Maringá, inventariou no total mais de 3 mil árvores, que representaram $5 \%$ da população de árvores de vias públicas da época. A amostragem realizada por esta pesquisa amostrou aproximadamente 90\% da população de árvores da cidade, amostrando mais árvores do que a população inteira estimada de 1988 (62.818 árvores), ou seja, a significância amostral foi considerada representativa da realidade da arborização urbana de Maringá-PR.

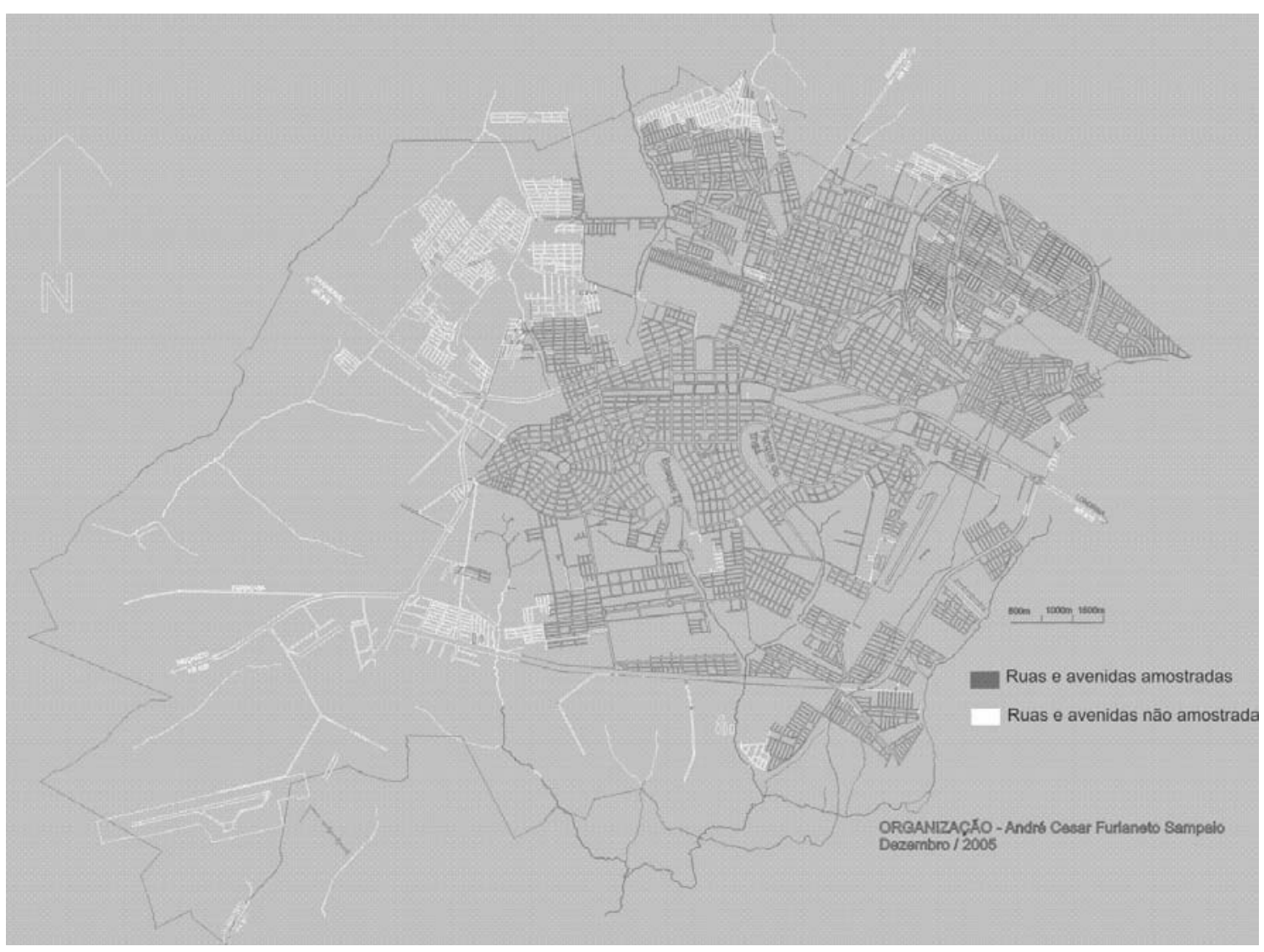

Figura 01 - Cidade de Maringá e a estimativa das ruas e avenidas amostradas pelo inventário.

\section{Composição, quantidade e distribuição da população amostrada}

Foram identificadas 113 espécies vegetais de porte arbóreo e arbustivo plantadas, num total de 93.261 árvores verificadas pelas vias de Maringá.

A diversidade de espécies em Maringá vem aumentando principalmente pelo fato de que a própria população acaba por fazer muitos plantios irregulares com espécies escolhida à gosto. De acordo com Milano (1988) a arborização de Maringá, possuía cerca de 60 espécies na arborização de vias públicas e atualmente com os dados deste trabalho temos 
113 espécies identificadas. As espécies mais encontradas continuam praticamente as mesmas verificadas por Milano.

Todos os registros da área pesquisada receberam um número identificador fornecido em mapa pela COPEL e tiveram seus dados cadastrados e analisados (tabela 1).

Tabela 1 - Classificação dos dados encontrados em toda área amostrada, quantidade e porcentagem.

$\begin{array}{lll}\text { Status do Registro } & \text { Quantidade }\end{array}$

\begin{tabular}{ccc}
\hline Regulares & 78.134 & 72,23 \\
Jovens & 15.127 & 13,98 \\
Ausentes & 10.440 & 9,65 \\
Cortadas & 3.759 & 3,48 \\
Mortas & 712 & 0,66 \\
\hline TOTAL & $\mathbf{1 0 8 . 1 7 2}$ & $\mathbf{1 0 0 , 0 0}$
\end{tabular}

Conforme os dados apresentados na tabela 1 existem na área amostrada de Maringá um total de 93.261 árvores, das quais 15.127 são jovens (mudas até 3 metros de altura) e 78.134 são consideradas já bem estabelecidas (Regulares - mais de 3 metros de altura) e sendo o restante da cifra total apresentado (14.911 registros) distribuído entre árvores que já foram cortadas, ausentes ou até mesmo mortas, ou seja, são espaços onde, provavelmente, poderia se ter novas árvores plantadas.

As 10 espécies mais freqüentes (tabela 2) tendo suas freqüências somadas resultam em $74,76 \%$ da arborização de vias públicas de Maringá, o que mostra que apesar de ter boa variabilidade de espécies (113 espécies) a composição geral fica concentrada em poucas espécies.

Tabela 2 - Freqüência em Porcentagem (F) das 10 principais espécies arbóreas encontradas em toda população amostrada.

\begin{tabular}{cccc}
\hline Nome Popular & Nome Científico & Total & $\mathrm{F}(\%)$ \\
\hline SIBIPIRUNA & Caesalpinia peltophoroides Benth. & 36.570 & 39,21 \\
IPÉ ROXO & Tabebuia avellanedae Lorentz ex & 9.595 & 10,28 \\
TIPUANA & Griseb. & 6.263 & 6,72 \\
OITI & Tipuana tipu (Benth.) Kuntze & 3.257 & 3,49 \\
FALSA MURTA & Licania tomentosa (Benth.) Fritsch & 2.965 & 3,18 \\
JACARANDÁ & Murraya paniculata (L.) Jack & 2.680 & 2,87 \\
LIGUSTRUM & Jacaranda mimosifolia D. Don & 2.596 & 2,78 \\
ALECRIM & Ligustrum lucidum W.T. Aiton & 2.560 & 2,74 \\
IPÊ AMARELO & Holocalyx balansae Micheli & 1.844 & 1,98 \\
& Tabebuia chrysotricha (Mart. ex A. DC.) & & 1,50 \\
FLAMBOYANT & Standl. & 1.397 & 74,76 \\
\hline & Delonix regia (Bojer ex Hook.) Raf. & &
\end{tabular}

As espécies Licania tomentosa (Oiti) e Murraya paniculata (Falsa Murta) de acordo com Milano (1988) não figuravam entre as espécies mais freqüentes, o que demonstra que 
nos últimos 18 anos essas espécies foram as mais plantadas e atualmente estão entre as 10 espécies mais freqüentes.

A somatória das freqüências das 10 principais espécies correspondem a $74,76 \%$ da população amostrada; a título de comparação em Águas de São Pedro a somatória das dez principais espécies perfizeram 48,33\% (BORTOLETO, 2004); em Jaboticabal o resultado foi de 71,25\% (SILVA FILHO, 2002); em Brasília a soma das treze principais espécies resultaram em apenas 48,3\% (RODRIGUES et al., 1994); em Piracicaba, onde o total de espécies foi pequeno, apenas 35 espécies, as treze principais espécies resultaram em 86,5\% da população (LIMA, 1993), ou seja, Maringá neste item se iguala a cidades onde o índice de biodiversidade e a qualidade da arborização não tiveram bons resultados, pois resultados bons na arborização viária foram encontrados em cidades como Águas de São Pedro e Brasília.

A espécie Caesalpinia peltophoroides (Sibipiruna), considerando toda a amostra, foi á única fora do padrão proposto por Grey e Deneke (1978) que permite uma freqüência de 10 até $15 \%$ em zonas urbanas de uma mesma espécie. Desta forma o problema da composição florística, de forma geral, ficou concentrado principalmente nesta espécie, porém, os dados permitiram a análise da composição florística em várias zonas (áreas compostas de vários bairros e delimitadas pela Prefeitura Municipal de Maringá), o que demonstrou que em várias localidades outras espécies também apresentam freqüências elevadas. Essa análise de composição florística por zonas da cidade serve de base para um planejamento mais adequado desta composição, permitindo que futuramente a composição florística seja bem equilibrada em termos de freqüência por espécie. (Figura 2). 


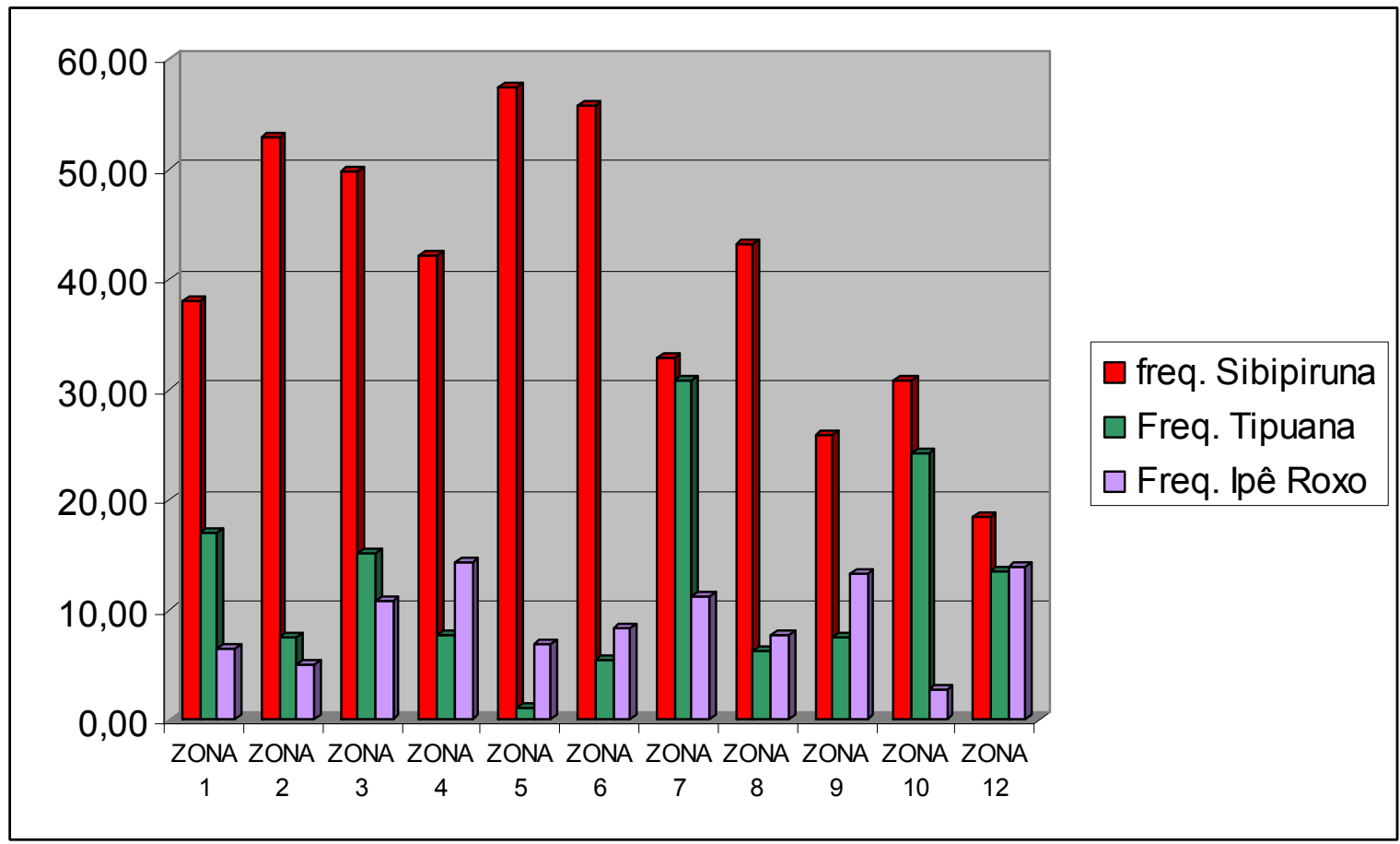

Figura 2 - Freqüência (\%) das espécies mais encontradas nas zonas da Área do Plano Piloto de Maringá - PR.

Podemos dizer que a situação dessa freqüência inadequada da espécie, principalmente, Caesalpinea peltophoroides é mais crítica do que a encontrada em outras cidades brasileiras. Enquanto na Estância de Águas de São Pedro a mesma espécie Caesalpinea peltophoroides também foi a espécie mais presente, mas com apenas 13,63\% (BORTOLETO, 2004); em Piracicaba Caesalpinea peltophoroides novamente com 52,3\%, o que já demonstra um caso mais grave do que o encontrado nesta pesquisa (LIMA, 1993).

\section{Qualidade das árvores}

Foi adotada uma avaliação individual das condições gerais das árvores de vias públicas que permitiu conhecer a qualidade geral da população (tabela 3).

Tabela 3 - Freqüência $(F)$ das condições gerais encontradas nas árvores da população amostrada, de Maringá-PR.

\begin{tabular}{ccc}
\hline Condição Geral & Quantidade & $\mathbf{F ~ ( \% )}$ \\
\hline Boas & 17.004 & 18,23 \\
Satisfatórias & 45.926 & 49,24 \\
Ruins & 30.331 & 35,52 \\
\hline TOTAL & $\mathbf{9 3 . 2 6 1}$ & $\mathbf{1 0 0 , 0 0}$
\end{tabular}

Existe uma porcentagem alta de árvores em condições ruins, o que indica que o manejo não esta adequado, favorecendo uma dispersão de pragas e doenças bastante agressivas. 
Comparando esse dado com os dados de Milano (1988) podemos ver indícios que realmente nos últimos anos aconteceram pioras significativas nas condições gerais da arborização de vias públicas, pois havia sido constatado por Milano (1988) que 51,9\% das árvores em Maringá podiam ser consideradas boas, 33,1\% satisfatórias e 13,8\% ruins.

Apesar do levantamento executado por esta pesquisa ter usado um sistema de avaliação das condições gerais um pouco diferente do usado por Milano (1988), com a comparação podemos formular uma hipótese de que as árvores que estavam satisfatórias na avaliação de Milano atualmente, em sua grande maioria, estão em estado ruim.

Em um estudo realizado por Castro (2004) sobre a presença de cancro nas árvores das zonas 1 e 2 se viu que 17,31\% das árvores da zona 1 tinham sintomas de cancro e $11,88 \%$ na zona 2 . Isso ajuda a complementar os resultados desta pesquisa, pois cancros associados a outras pragas e doenças estão presente na arborização e levaram a resultados de freqüência alta de árvores com condições gerais ruins.

\section{Incidência de cupins}

Foi visto que 12.797 árvores que representam $13,72 \%$ da população amostrada tiveram presença ou vestígios de cupins. O que é um número considerável e que mostra claramente que a situação das árvores é crítica, pois esses cupins comumente só atacam árvores em estado de degradação, principalmente com apodrecimentos na madeira. Em zonas centrais, que são onde estão às árvores mais velhas, essa freqüência de cupins se mostrou mais alta.

Galvão et al (2006), em estudo realizado na zona 1 de Maringá-PR, encontrou apenas uma espécie de cupim, denominada Nasutitermes corniger, nas árvores de vias públicas de Maringá. Essa espécie de cupim arborícola encontrada só se alimenta de matéria morta. Isso indica que existe muita matéria morta nas árvores afetadas e que uma prioridade de vistoria deve ser dada a essas árvores.

\section{Indicadores de qualidade do ambiente}

Alguns indicadores da boa qualidade do ambiente como musgos, liquens, e epífitas em geral, mostraram-se com uma freqüência bastante alta, principalmente musgos e liquens que tiveram mais de $70 \%$ de freqüência, mostrando que graças a uma arborização de grande porte e densa a cidade de Maringá tem indicativos fortes de um bom clima e pouca poluição atmosférica.

\section{Índices de área verde}

Segundo o IBGE (2005), em um censo realizado no ano de 2004, Maringá apresentava uma população estimada de 318.952 habitantes em uma área de unidade 
territorial de 487,93 $\mathrm{Km}^{2}$. De acordo com a Prefeitura Municipal de Maringá (2005) a área urbana de Maringá, incluindo novos bairros, é de 135,86 Km².

De acordo com Milano (1988) as árvores de vias públicas (copas) e as áreas verdes (parques e praças) de Maringá cobriam $13,4 \%$ da área urbana e resultavam em um índice de $20,6 / \mathrm{m}^{2} / \mathrm{hab}$. Considerando apenas as árvores de vias públicas Milano (1988) encontrou um índice de $13,9 / \mathrm{m}^{2} / \mathrm{hab}$.

A área verde estimada de Maringá, considerando apenas as árvores de vias públicas, é hoje de aproximadamente $25,24 / \mathrm{m}^{2} / \mathrm{hab}$, ou seja, acima do índice verificado por Milano $\left(13,9 / \mathrm{m}^{2} / \mathrm{hab}\right)$. Contabilizando a área de parques e praças verificada por Milano $\left(1.931 .145,6 \mathrm{~m}^{2}\right)$ chegamos a um índice de $31,29 / \mathrm{m}^{2} / \mathrm{hab}$, ou seja, temos um índice de área verde por habitante maior atualmente.

Não existe até o momento uma padronização nacional para o cálculo deste índice, o que dificulta qualquer comparação com outros municípios, porém, a Associação Nacional de Recreação dos Estados Unidos no Congresso Internacional de Recreação, realizado em 1956 na Filadélfia recomendou um índice de 28 a $40 \mathrm{~m}^{2}$ de área verde por habitante. Cavalheiro (1982) indicou que as cidades alemãs, em termos de cobertura verde total, atingissem um índice médio de $33,5 \mathrm{~m}^{2}$ de área verde por habitante.

\section{CONCLUSÃO}

Ficou constatado que atualmente a situação é bem diferente daquela mencionada na tese defendida por Milano (1988), esta extremamente agravada aquela pela ausência de políticas e de ações efetivas, porém, a quantidade de árvores e os benefícios da arborização continuam presentes na cidade, mas é notável a queda de qualidade nas condições dessas árvores. Evidentemente, tanto a infra-estrutura quanto a mão de obra da Prefeitura Municipal, embora qualificada, não se mostram suficientes para garantir a gestão da arborização de vias públicas.

O inventário efetuado mostrou bastante eficácia, dando resultados de extrema precisão e facilidade na localização dos principais problemas, pois a localização de cada árvore ficou cadastrada em um banco de dados que poderá ajudar no planejamento do manejo da arborização urbana de Maringá. Muitos problemas logísticos e de velocidade no cadastramento de dados foram verificados, o que demonstra que inventários censitários em cidades de porte médio e grande, são bastante complexos em termos de previsibilidade de tempo de cadastro, principalmente pelo fato da logística ser um fator de custo financeiro alto e de difícil planejamento. 
Com o banco de dados elaborado e mapas digitalizados será possível a implantação de um Sistema de Informações Geográficas (SIG), que poderá mostrar com maior eficácia a localização de muitas informações da arborização na cidade.

Os principais problemas encontrados foram à freqüência da espécie Caesalpinea peltophoroides $(39,21 \%)$ que ficou bem acima de todas as outras espécies; e um número bastante expressivo de árvores com condições ruins (35,52\%), o que mostra que um manejo e planejamento mais adequado deve ser elaborado e executado. A presença de cupins em $13,72 \%$ das árvores (contabilizadas nas árvores em condições ruins) demonstra que muitas árvores estão em estado de degradação e apodrecimento.

\section{AGRADECIMENTOS}

A Deus e nossas famílias.

Ao Reitor Wilson de Matos Silva e ao Centro Universitário de Maringá (CESUMAR), por colaborar e dar sustentabilidade ao desenvolvimento desta pesquisa.

As empresas financiadoras Companhia de Energia Elétrica do Paraná (COPEL), Gelita do Brasil e Transporte Coletivo Cidade Canção (TCCC)

Ao colega de trabalho e amigo Marcio Geovani Tavares de Assunção por sua dedicação e colaboração imprescindível a esta pesquisa.

Aos alunos bolsistas do "Projeto Árvore" que coletaram os dados desta pesquisa e de outras com muito empenho e dedicação: Abdiner Tucci Antunes, Alex Martins Vieira, Aline Lie Koseki, Ana Maria Fagundes da Silva, Anejoyce Bertão Gallo, Dayane Santos Barroso, Diógenes de Paiva Monteiro, Emanuel Giovani Gafofo Silva, Fabio Eduardo F. Santos, Felipe Galvão Duarte, Flávia Campos Canteri, Giovanna Caputo dos Anjos Almeida, Jamile Corina Fanhani, Jane Moreschi, Jaqueline Franco Reis, Kátia Roberta Fávoro, Leonardo Caparroz Cangussu, Luiz Henrique Begnosi, Marcelo Ushijima Kuwaoka, Nataly S. Pógere, Odilon Groxiatti Tudini, Paula Renata Leoni, Sara Raquel G. de Souza, Tatiane Takahashi Nunes e Vanessa de Souza

Ao professores e colegas do Cesumar Empresarial que apoiaram significativamente o desenvolvimento deste trabalho.

A todas as pessoas que possa ter esquecido, pois recebi ajuda fundamental de muitas.

\section{REFERÊNCIAS}

ANDRADE T. O. Inventário e Análise da arborização viária da Estância turística de Campos de Jordão - SP, Piracicaba, 2002. 112p. (Dissertação de mestrado - Escola superior de agricultura "Luiz de Queiroz" Universidade de São Paulo). 
BORTOLETO, SILVANA. Inventário Quali-quantitativo da arborização viária de Águas de São Pedro - SP, Piracicaba, 2004. Tese (Mestrado Agronomia) - Escola Superior de Agronomia Luiz de Queiroz - Universidade de São Paulo - Área de Fitotécnica, Piracicaba, 2004.

CASTRO, R. M. DE. Estudo comparativo do cancro em árvores de acompanhamento viário em duas áreas distintas - Central e residencial - na cidade de Maringá-PR. Maringá, UEM., 2004. 42 p. (Dissertação de mestrado. Universidade Estadual de Maringá)

CAVALHEIRO, F. O Planejamento de espaços livres: o caos de São Paulo. In: CONGRESSO NACIONAL SOBRE ESSENCIAS NATIVAS, CAMPOS DO JORDÃO, 1982. Anais. São Paulo, 16(A-3): 1819 - 1830, 1982.

COSTA, L.A.C.; HIGUCHI, N. Arborização de ruas de Manaus: Avaliação qualitativa e quantitativa. REVISTA ÁRVORE, v 23 n. 2 p. 223 - 232, 1999

DE ANGELIS, B. L. D. A praça no contexto das cidades o caso de Maringá - PR. 2000 Tese (Doutorado em Geografia Humana) - Faculdade de Filosofia, Letras e Ciências Humanas, Universidade de São Paulo, São Paulo, 2000.

DE ANGELIS NETO, G.; DE ANGELIS, B. L. D. Os instrumentos urbanísticos e a arborização urbana. In: Congresso Brasileiro de Arborização Urbana 5. 2000, Rio de Janeiro. Anais. Rio de Janeiro: Sociedade Brasileira de Arborização urbana, 2000.

DEPARTAMENTO DE PARQUES E JARDINS - DPJ/ Prefeitura Municipal de Curitiba Arborização urbana da Cidade de Curitiba. Curitiba - PMC, 1977.

DOMINGUES, Z. H. Produção de mudas para Arborização Urbana. In. Encontro Nacional Sobre Arborização Urbana 2. Anais. Maringá PMM, 236 p: 9-19 1987.

GALVÃO, F. D.; SANTOS G. A.; ROSADO R. R.; DELARIVA R. L.; SAMPAIO A. C. F. Cupins (Insecta: Isoptera) na Arborização Urbana da Zona 1 de Maringá-PR. Revista em Agronegócios e Meio Ambiente, v. 1, n. 1, p. 87-99, jan./abr. 2008.

GREY, G. W. \& DENEKE, F. J. Urban forestry. New York, John Wiley, 1978. 
GRIFFITH, J. J. \& SILVA, S. M. F. da. Mitos e métodos no planejamento de sistemas de áreas verdes. In : Encontro Nacional Sobre Arborização Urbana, 2., Maringá, 1987. Anais. Maringá, P. 34 - 42, 1987.

INSTITUTO BRASILEIRO DE GEOGRAFIA E ESTATÍSTICA (IBGE). Disponível em < http://www.ibge.gov.br/cidadesat/default.php. Acesso em 15 de outubro de 2005.

LIMA, A. M. L. P.; COUTO H. T. Z. do; ROXO, J.L.C. Análise das espécies mais freqüentes da arborização viária na zona urbana central do município de Piracicaba - SP. In: CONGRESSO BRASILEIRO DE ARBORIZAÇÃO URBANA, 2; 1994, Anais. São Luis: Sociedade Brasileira de arborização urbana, p. 555-578, 1994.

MILANO, M. S. Avaliação Quali-Quantitativa e manejo da Arborizaçào Urbana : Exemplo de Maringá -PR. Curitiba, UFPR, 1988, 120 p. ( Tese de Doutorado apresentada ao Curso de Pós-Graduação em Engenharia Florestal do Setor de Ciências Agrárias da Universidade Federal do Paraná). 1988.

MILANO, M. S. Curso de manejo de áreas silvestres. Curitiba, FUPEF, 1983. 102 p.

PREFEITURA MUNICIPAL DE MARINGÁ. Disponível em < http://www.maringa.pr.gov.br/. Acesso em 15 de outubro de 2005.

SAMPAIO, A. C. F. Relatório Final Projeto Árvore - Censo das árvores urbanas de Maringá - PR. Maringá, CESUMAR, 2006.

SILVA FILHO D. F. Cadastramento informatizado, sistematização e análise da arborização das vias públicas da área urbana do município de Jaboticabal - SP, Jaboticabal, 2002. 81 p. (Dissertação de mestrado - Faculdade de Ciências Agrárias e veterinárias, Universidade Estadual Paulista “Julio de Mesquita Filho"). Jaboticabal-SP, 2002

TAKAHASHI, L. T. A Arborização Urbana e a Distribuição de Energia Elétrica em dois Bairros da Cidade: Jardim Alvorada e Zona 5. 1997 (Monografia especialista em Geografia do Estado do Paraná), Maringá, 1997. 